Article

\title{
Impact of Low Molecular Weight Acids on Oil Impregnated Paper Insulation Degradation
}

\author{
Kakou D. Kouassi ${ }^{1}$, Issouf Fofana ${ }^{2, *}$ (D), Ladji Cissé ${ }^{1}$, Yazid Hadjadj ${ }^{3}$, Kouba M. Lucia Yapi $^{2}$ \\ and K. Ambroise Diby ${ }^{1}$ \\ 1 Ufr-SSMT Laboratory of Physics Condensed Matter and Technology, Université Félix Houphouet Boigny de \\ Cocody-Abidjan, 22 BP 582 Abidjan 22, Côte d'Ivoire; lorellmongoua@gmail.com (K.D.K.); \\ ladjic@hotmail.com (L.C.); dibyka@yahoo.fr (K.A.D.) \\ 2 Research Chair on the Aging of Power Network Infrastructure (ViAHT), Université du Québec à Chicoutimi, \\ Chicoutimi, QC G7H 2B1, Canada; KoubaMarieLucia1_Yapi@uqac.ca \\ 3 Measurement Sciences and Standards, National Research Council Canada (NRC), \\ Ottawa, ON K1A 0R6, Canada; yazidhad@yahoo.com \\ * Correspondence: ifofana@uqac.ca; Tel.: +1-418-545-5011
}

Received: 30 April 2018; Accepted: 31 May 2018; Published: 6 June 2018

check for updates

\begin{abstract}
Aging of a power transformer's insulation system produces carboxylic acids. These acids - acetic, formic and levulinic — are absorbed by the paper insulating material, thus accelerating the degradation of the whole insulation system. In this contribution, the effect of these acids on the aging of oil-impregnated paper insulation used in power transformer is reported. A laboratory aging experiment considering different concentrations of these three acids was performed to assess their effect on the insulation system's degradation. Each acid was individually mixed with virgin oil, and a mixture of acids was also blended with oil. The paper's degradation was assessed by the degree of polymerization (DPv). It was found that the DPv of paper aged with formic acid decreased much faster in comparison to the other acids.
\end{abstract}

Keywords: power transformer; oil-paper insulation; carboxylic acids; acetic acid; formic acid; levulinic acid; degree of polymerization

\section{Introduction}

Many power transformers installed around the world have exceeded their estimated design life, as the majority of them are approaching or exceeding the age of 25-30 years. However, these important machines are still in service well beyond their designed lifetime. With increasing age and exacerbated by the growing demand in electricity, there are potential risks of extremely high monetary losses due to unexpected failures and outages. Because most failures of aging power transformers are due to the degradation of its insulation system, it has become important to understand the aging of paper insulation in order to prolong the life of transformers, and to know the condition of their insulation, by means of suitable diagnostic tests. Increasing requirements for appropriate tools allowing diagnosing of power transformers non-destructively and reliably has promoted the development of modern complementary diagnostic techniques [1,2]. Research activities are still in progress worldwide to improve these techniques [1-6].

Transformer life/ageing is mainly related to the degradation of the oil paper insulation system. Heat, water, oxygen and aging products are severely contributing to transformer aging [7]. It is now well established that insulation aging is catalyzed by moisture, copper/copper alloys in aluminum windings and iron (which are primary transformer components), and oxygen [8]. The insulation aging may be subdivided in three processes: 
(1) Pyrolysis, promoted by heat;

(2) Hydrolysis, by reactions with water; and

(3) Oxidation by reactions with oxygen.

These processes are accelerated by heat, ageing by-products, dirt, vibrations/overload, and electrical stress/voltage waves, etc. [8].

Mineral oil used in transformers is mainly composed of three types of hydrocarbons. These hydrocarbons are paraffins, naphthenes and aromatics. They consist in 18 carbon atoms on average [9]. The insulating paper material used in power transformers consists largely of cellulose. Cellulose consists mainly as a polymer, formed from repeated monomers of glucose. As the oxidation level of in-service oil increases, polar compounds-particularly organic acids-form in the oil. During the aging of the oil/paper insulation system, acids are produced from chemical reactions. Carboxylic acids are generated from oxidation of the transformer oil or hydrolysis of its paper insulating material [10]. Because oil is more easily accessible, oil analyses are among the most used diagnostic techniques $[1,2]$. About $70 \%$ of the diagnostic information can be identified by oil analysis [1]. Among these techniques, the measurement of the total acid number (TAN) is frequently used to monitor the level of degradation of the insulating oil. Acid generation accelerates when water and oxygen are present. Acid in turn causes acid-hydrolysis. It is recommended that the oil be reclaimed when the acid number reaches $0.15 \mathrm{mg}$ of potassium hydroxide $(\mathrm{KOH}) / \mathrm{g}$ for power transformers with nominal voltages above 400 $\mathrm{kV}, 0.2 \mathrm{mg}$ of $\mathrm{KOH} / \mathrm{g}$ for 170 to $400 \mathrm{kV}$, and $0.3 \mathrm{mg}$ of $\mathrm{KOH} / \mathrm{g}$ for 72.5 to $170 \mathrm{kV}$ [11].

Oil oxidation also produces low molecular weight acids which degrade the whole insulation. The TAN (consisting of large and low molecular weight acids) is the measure of acid concentration in a non-aqueous solution. The procedure involves determining the amount of potassium hydroxide $(\mathrm{KOH})$ base required to neutralize the acid in one gram of an oil sample. The standard unit of measure is $\mathrm{mg} \mathrm{KOH} / \mathrm{g}$. However, the oxidation of oil produces two types of acids: low molecular weight acids (LMA) and high molecular weight acids (HMA) (stearic acid $\left[\mathrm{CH}_{3}\left(\mathrm{CH}_{2}\right) 16 \mathrm{COOH}\right]$ ) or naphthenic acids $\left[\mathrm{R}\left(\mathrm{C}_{5} \mathrm{H}_{8}\right)\left(\mathrm{CH}_{2}\right) \mathrm{nCOOH}\right][12,13]$.

Three main reactions that could break this polymer chain are oxidation, pyrolysis and hydrolysis [14,15]. Acid hydrolysis degrades paper insulation by producing carboxylic acids such as formic and levulinic acids, which are low molecular weight acids (LMA). These carboxylic acids accelerate the degradation of paper in turn $[12,16]$. Actually, the "end-of-life" of the transformer = "end-of-life" of cellulose-based paper isolation [1,2].

High molecular weight acids are hardly soluble in oil and are not aggressive. Therefore, they do not intervene much in the degradation of the paper insulation [17,18]. On the contrary, low molecular weight acids (up to five carbon atoms) are more hydrophilic and have a greater influence on the degradation rate of paper throughout acid hydrolysis. The accumulation of acids in oil accelerates formation of insoluble deposits (x-waxes), which reduce the dielectric strength in turn. These deposits could also reduce heat transfer if they are deposited on paper or inside radiator pipes, increasing thermal degradation of paper insulation [19].

In recent years, research directed towards biodegradable liquids as alternatives to mineral oils has become popular. Significant differences exist between esters and typical mineral oils-especially the aniline point, flash point, interfacial tension, acidity, pour point, and viscosity. For example, it has been reported that the aging rate of the solid insulation in natural esters, even with a dark color and a very high acid value, is lower than that of the mineral oil impregnated solid insulation with a lower acidity value [20]. The TAN in oil is consequently not currently used to monitor aging of paper insulation, because the correlation between acidity and aging rate has not been fully determined [16]. Paper may contain $50 \%$ of acidity present in transformer insulation system. In addition, acid analyses indicate that hydrophilic acids were mainly concentrated in paper insulation. As a result, the majority of low molecular weight acids detected are located in paper. Also, the concentration of low molecular weight acid in paper is greater than in oil. Consequently, the polymerization degree (DPv) of paper insulation decreases [21]. 
To date, different aging indicators are being used to monitor transformer lifetime. Direct measurements to ensure that the paper continues to provide effective insulation for the transformer are performed through tensile strength or degree of polymerization, measured by the viscometric method (DPv). The DPv, which represents the average number of glucose units per cellulose chain, is directly correlated to the mechanical strength of paper [1]. To overcome the problems related to direct measurements, many studies were conducted to develop alternative indirect techniques for assessing the condition of solid insulation [1]. This article focuses specifically on the impact of low molecular weight acids on the degradation of oil-impregnated paper. The influences of three different LMAs—namely the acetic, formic and levulinic acids—on the DPv of Kraft paper impregnated with mineral oil are investigated. To simulate critical situations, a naphtenic-based mineral oil was used and samples with $0.2 \mathrm{mg} \mathrm{KOH} / \mathrm{g}$ and $0.40 \mathrm{mg} \mathrm{KOH} / \mathrm{g}$ of acid concentrations of the three acids, either individually or combined, were considered to simulate extreme degradations. A mixture of these three acids was also considered.

\section{Background on Carboxylic Acids Formation in Transformer Oil}

Mineral oil is mainly composed of three types of hydrocarbons, namely paraffins, naphthenes and aromatics, with an average number of carbon atoms equal to 18 . When these hydrocarbon molecules $\left(\mathrm{C}_{\mathrm{x}} \mathrm{H}_{\mathrm{y}}\right)$ and Oxygen molecules $\left(\mathrm{O}_{2}\right)$ react chemically, oil begins to deteriorate. This reaction forms the following compounds [8]:

- Acid deposits generate colloids. This colloidal suspension reduces the dielectric strength of the insulation system of the power transformer. Insoluble suspensions worsen the cooling effectiveness of the power transformer. The temperature increase degrades cellulose and acts as a catalyst for further oxidation.

- Water degrades cellulose reducing breakdown voltage and acts as a catalyst for oxidation. Water and acids have a multiplicative effect on the ageing rate [14].

- $\operatorname{Gases}\left(\mathrm{CO}, \mathrm{CO}_{2}, \mathrm{O}_{2}, \mathrm{H}_{2}, \mathrm{CH}_{4}, \mathrm{C}_{2} \mathrm{H}_{4}, \mathrm{C}_{4} \mathrm{H}_{6}, \mathrm{C}_{6} \mathrm{H}_{8}\right)$ that are dissolved in the oil.

- Acids promote corrosion and also act as catalysts for the oxidation of oil.

All of these compounds, including carboxylic acids, are formed by a series of radical reactions [22].

Carboxylic acids formed in oil are classified into two groups: low molecular weight (LMA) and high molecular weight (HMA). Low molecular weight carboxylic acids (LMA) have an affinity with cellulose (paper) and water because of their ability to bond with the hydroxyl group ( $-\mathrm{OH})$. They react chemically to give a proton $\left(\mathrm{H}^{+}\right)$, as described by acid-base theory of Brønsted-Lowry [14,23].

\section{Degradation of Cellulose}

\subsection{Swelling of Cellulose}

Cellulose is a natural polymer. Macromolecules of cellulose are present in all plant species in the form of fibrils with very variable proportions. Wood (softwood or hardwood) contains between $40 \%$ and $50 \%$ of their weight as dry cellulose, whereas cotton fibers contain between $85 \%$ and $95 \%$ [24] of their weight. Cellulose is a polysaccharide of $\beta$-D glucans series [25]. Its repetitive pattern is cellobiose.

Cellulose has crystalline regions and amorphous regions. The hydrogen bonds are much more numerous in crystalline regions. Cellulose crystallinity degree varies from $40 \%$ to $50 \%$ for wood, $60 \%$ for cotton and more than $70 \%$ for certain seaweeds [26].

The biphasic structure of cellulose (both crystalline and amorphous) induces a two-step penetration of compound within cellulose. The first and easiest step is penetration of the amorphous zone of cellulose. It causes inter-crystalline swelling, which results in cleavage of $\beta 1-4$ glucosidic bond, hence depolymerization of the polymer chain. When compound penetrates crystalline regions, it induces intra-crystalline swelling. All compounds cannot reach the inner zone of crystal. Water, for example, only causes inter-crystalline swelling of cellulose fiber [27]. However, some compounds are 
able to pass through the crystallinity barrier and cause intra-crystalline swelling. Although penetrating cellulose deep within its structure, they are not able to dissolve it.

\subsection{Acid Hydrolysis}

The insulating paper consists of about $80 \%$ cellulose, $12 \%$ hemicelluloses, $8 \%$ lignin and certain mineral substances [24]. The aging of this insulating material has an impact on its electrical and mechanical strength. However, the main degradation factor of cellulose is acid hydrolysis, requiring water and acids [16]. Cellulose degradation will form more low molecular weight acids, which will remain absorbed in paper and accelerate the degradation of cellulose in turn [28,29].

Indeed, acid transfers a proton to water, forming hydronium, which then transfers the proton to cellulose, initiating chain splitting. According to the Bronsted-Lowry acid-base theory, the acid could transfer the proton directly to the cellulose, without an intermediate reaction with water [30]. However, water is a better acceptor of protons than cellulose because it is more polar. It is important to remember that there is a greater difference in electronegativity between oxygen and hydrogen in water than between oxygen and carbon in cellulose. The proton will share electrons with oxygen in the cellulose until the water causes the chain to split. Hydronium is particularly damaging because, after donating a proton to the cellulose, the remaining water molecule can then react with the cellulose. Note that a molecule of water is consumed during the chain scission, while the $\mathrm{H}+$ ion is recovered. The $\mathrm{H}+$ ion concentration remains unchanged. According to this reaction mechanism, the rate of degradation of the paper will depend on the concentration of water and $\mathrm{H}+$ ions dissociated from the acids.

\section{Materials and Methods}

\subsection{Oil and Paper Sample Preparation}

The mineral oil used in this contribution is the Nytro Polaris GX. This oil was degassed and dehumidified for $48 \mathrm{~h}$. Kraft paper samples had a surface area of $8 \times 8 \mathrm{~cm}^{2}$ were prepared. Paper and pressboard were dried in oven at $110^{\circ} \mathrm{C}$ under vacuum for $24 \mathrm{~h}$. The impregnation process was performed under vacuum. Usually, manufacturers establish a mass ratio of paper and oil according to the rating of the unit. In our investigations, the mass ratio between the cellulose insulation and oil used in these was 20:1. So, a $2000 \mathrm{~mL}$ of oil corresponding to a mass of $1812 \mathrm{~g}$ was used. This amount of oil corresponds to a mass of $90.60 \mathrm{~g}$ (paper + cardboard).

The impregnation of the paper samples with dried oil was performed under vacuum, in the same vacuum oven.

\subsection{Oil Acidity Preparation}

In addition to oil-free acid sample, two concentrations of each type of acid were prepared. Table 1 summarizes the chemical properties and the weight/volume of each acid added into $2 \mathrm{~L}$ of oil to obtain an acidity concentrations of $0.2 \mathrm{mg} \mathrm{KOH} / \mathrm{g}$ and $0.4 \mathrm{mg} \mathrm{KOH} / \mathrm{g}$ respectively.

Table 1. Summary of acids masses to be added in $2000 \mathrm{~mL}$ oil.

\begin{tabular}{cccccccc}
\hline & & & \multicolumn{2}{c}{ TAN (0.2 mg KOH/g) } & \multicolumn{2}{c}{ TAN (0.4 mg KOH/g) } \\
\cline { 5 - 8 } Acids & Purity & $\begin{array}{c}\text { Molar Mass } \\
(\mathbf{g} / \mathbf{m o l})\end{array}$ & $\begin{array}{c}\text { Density } \\
\left(\mathbf{g} / \mathbf{c m}^{\mathbf{3}} \mathbf{)}\right.\end{array}$ & $\begin{array}{c}\text { Weight } \\
\mathbf{( m g )}\end{array}$ & $\begin{array}{c}\text { Volume } \\
(\mathbf{m L})\end{array}$ & $\begin{array}{c}\text { Weight } \\
\mathbf{( m g )}\end{array}$ & $\begin{array}{c}\text { Volume } \\
(\mathbf{m L})\end{array}$ \\
\hline Acetic acid & 0.997 & 60.05 & 1.0492 & 389.0364 & 0.3707 & 778.0728 & 0.7414 \\
Formic acid & 0.88 & 46.025 & 1.22 & 337.7568 & 0.2768 & 675.5136 & 0.5538 \\
Levulinic acid & 0.98 & 116.11 & 1.134 & 765.2076 & 0.6747 & 1530.4152 & 1.3494 \\
\hline
\end{tabular}

Oil acidity preparation objective was to determine the amount of the acid when oil total acid number is known. This will allow preparing oil samples with the following acidity levels, which will be used for measurements: 
- $\quad$ Paper with virgin oil,

- Paper with oil containing acetic acid of $0.20 \mathrm{mg} \mathrm{KOH} / \mathrm{g}$ and $0.40 \mathrm{mg} \mathrm{KOH} / \mathrm{g}$,

- Paper with oil containing formic acid of $0.20 \mathrm{mg} \mathrm{KOH} / \mathrm{g}$ and $0.40 \mathrm{mg} \mathrm{KOH} / \mathrm{g}$,

- Paper with oil containing levulinic acid of $0.20 \mathrm{mg} \mathrm{KOH} / \mathrm{g}$ and of $0.40 \mathrm{mg} \mathrm{KOH} / \mathrm{g}$,

- Paper with oil containing the mixture of acid: $(0.20 \mathrm{mg} \mathrm{KOH} / \mathrm{g}$ of acetic acid $)+(0.20 \mathrm{mg} \mathrm{KOH} / \mathrm{g}$ of formic acid $)+(0.20 \mathrm{mg} \mathrm{KOH} / \mathrm{g}$ of levulinic acid $)$.

The samples were aged in a convection oven at a temperature of $115^{\circ} \mathrm{C}$ for a total time of $2000 \mathrm{~h}$. Sampling was carried out every $500 \mathrm{~h}$. A sample of each concentration was left at ambient temperature during $72 \mathrm{~h}$ to assess the effect of the acids on the insulation system. A Karl Fisher $831 \mathrm{KF}$ coulometric titrator carried out the water content measurement according to ASTM (American Society for Testing Materials) D1533 standard.

The acidity measurement in transformer oil was performed according to ASTM D974 standard. An automated 862 Compact Titro-sampler system for titration the oil solution was used.

A capillary viscometer (Cannon-Fenske Routine) was used to measure the degree of polymerization (DPv), according to ASTM D4243 standard.

\section{Results and Discussion}

\subsection{Assessing Moisture in Paper during Aging}

Figure 1a-c shows the moisture changes in paper within aged oils. Three acids (formic, acetic and levulinic) individually mixed with various concentrations, a mixture of the three of them, and virgin oil (acid-free) were considered.

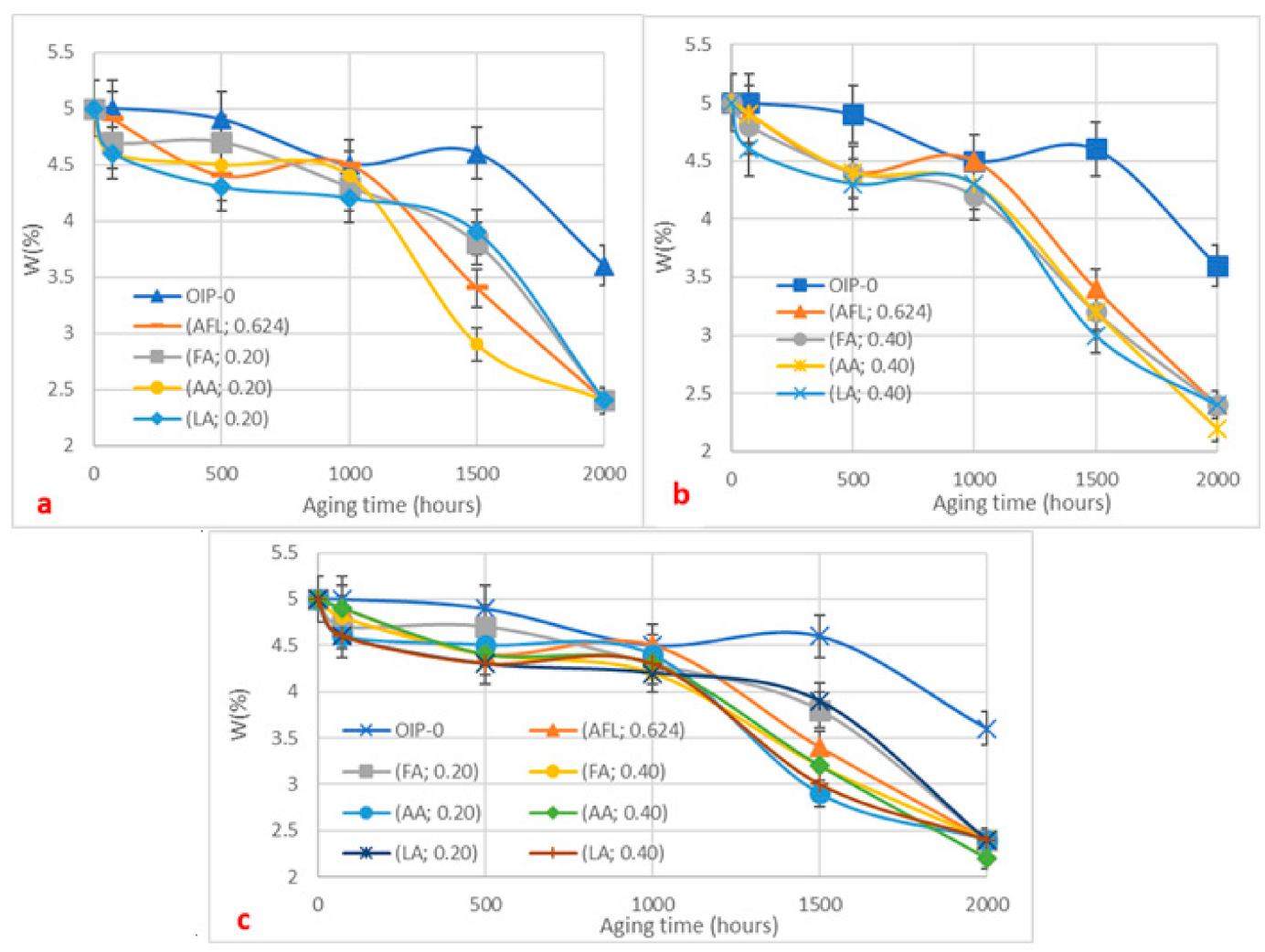

Figure 1. Moisture in paper as function of oil aging time within both acid contents: (a) $0.20 \mathrm{mg} \mathrm{KOH} / \mathrm{g}$ and (b) $0.40 \mathrm{mg} \mathrm{KOH} / \mathrm{g}$ for three different acids (formic, acetic and levulinic), acid mixture and also for acid-free oil. The results are summarized in Figure (c) for better comparison. 
Figure 1a shows a decrease in moisture during aging time for all acids, with their various acid contents.

Water molecule absorption leads to polymer chain scission which in turn promotes paper insulation aging. So, polymer chain scission can be related to the reduction in moisture [23]. Figure 1b,c show that moisture in paper within virgin oil (HNAP) remained higher during aging. The amount of moisture decreased with aging time whatever the acid contents.

\subsection{Total Acid Number (TAN) of Oil for Unaged Samples}

Figure $2 \mathrm{a}-\mathrm{c}$ presents acidity comparison before and after $72 \mathrm{~h}$ of exposure at room temperature. Three acids (formic, acetic and levulinic) individually mixed with various concentration, along with the mixture of them and virgin oil (acid-free) were considered. It is noted that after $72 \mathrm{~h}$ of aging at room temperature, acidity was lower in oils within formic acid for both concentrations $(0.20 \mathrm{mg} \mathrm{KOH} / \mathrm{g}$ and $0.40 \mathrm{mg} \mathrm{KOH} / \mathrm{g}$ ). Formic acid being of low molecular weight, and therefore highly soluble in oil. Accordingly, it could be absorbed readily by the insulating paper [12]. The same conclusion can be drawn for acetic acid with $0.20 \mathrm{mg} \mathrm{KOH} / \mathrm{g}$ in oil compared to levulinic acid with same acid content. However, for higher concentrations of acid i.e., $0.40 \mathrm{mg} \mathrm{KOH} / \mathrm{g}$, the acidity of oil with acetic acid was higher than with levulinic acid.

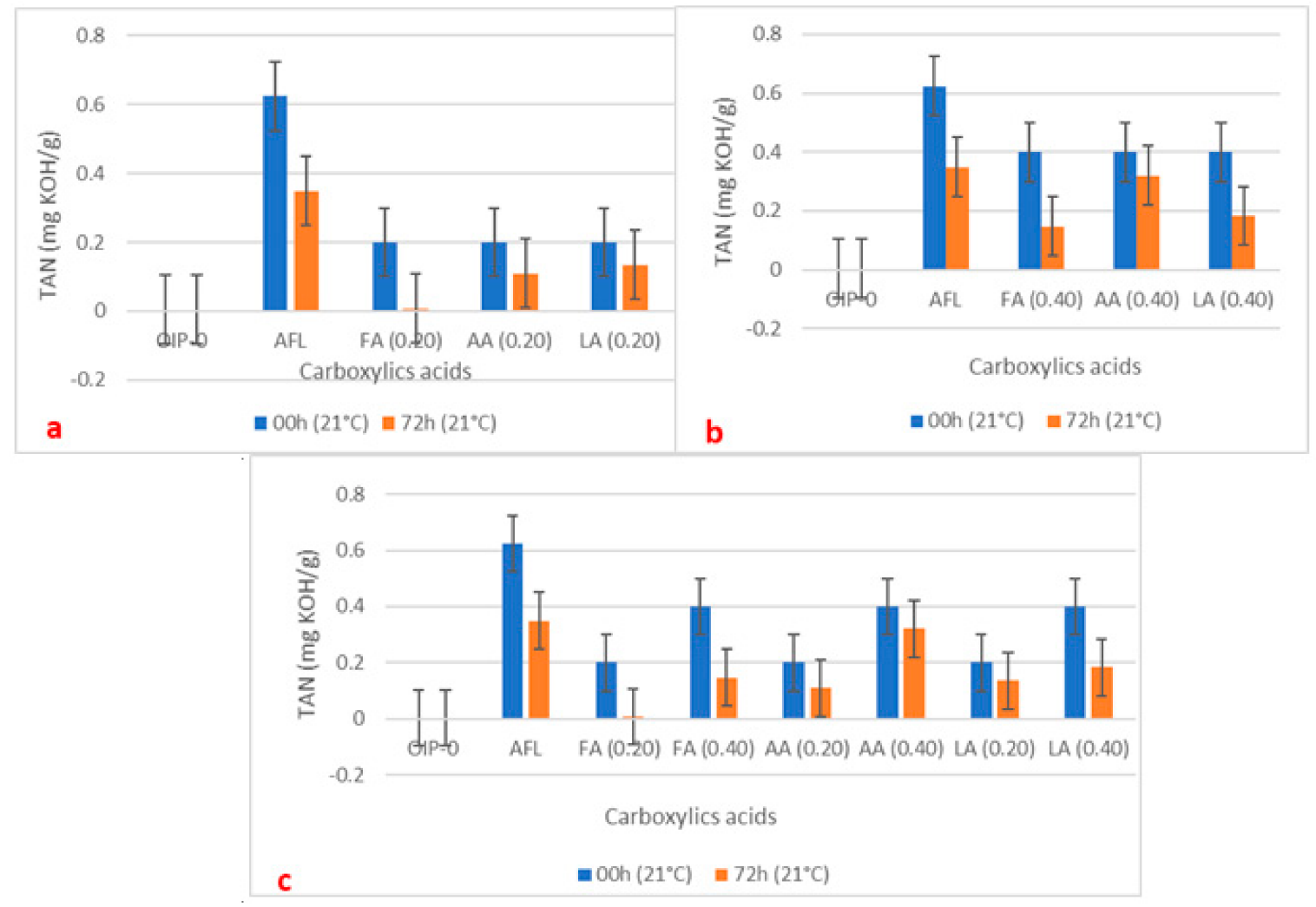

Figure 2. Acidity comparison before and after $72 \mathrm{~h}$ of exposure at room temperature: (a) $0.20 \mathrm{mg}$ $\mathrm{KOH} / \mathrm{g}$ and (b) $0.40 \mathrm{mg} \mathrm{KOH} / \mathrm{g}$ for three different acids (formic, acetic and levulinic), acid mixture and also for acid-free oil. The results are summarized in Figure (c) for better comparison.

\subsection{Degree of Polymerisation (DPv) before Thermal Aging}

Figure 3a-c depicts the comparison of paper's DPv before and after $72 \mathrm{~h}$ of exposure at room temperature. Three acids (formic, acetic and levulinic) individually mixed with various concentration, along with the mixture of them and virgin oil (acid-free) were considered. These figures show that the degree of polymerization is lower for paper aged within oils containing formic acid after $72 \mathrm{~h}$ for both 
concentrations $(0.20 \mathrm{mg} \mathrm{KOH} / \mathrm{g}$ and $0.40 \mathrm{mg} \mathrm{KOH} / \mathrm{g})$. Formic acid is highly soluble in oil, and causes chain scission of the polymer chain of insulating paper [12]. On one hand, the DPv of paper with levulinic acid was lower than of paper exposed to acetic acid of $0.20 \mathrm{mg} \mathrm{KOH} / \mathrm{g}$. On other hand, the $\mathrm{DPv}$ of the paper with levulinic acid was higher than that of paper exposed to acetic acid of $0.40 \mathrm{mg}$ $\mathrm{KOH} / \mathrm{g}$. For acid concentrations of $0.20 \mathrm{mg} \mathrm{KOH} / \mathrm{g}$, levulinic acid was more aggressive compared to acetic acid. This is in agreement with findings by Lungaard et al. $[8,10,16,18]$ who reported that Kraft paper more readily absorbs formic acid than the acetic and levulinic acids.

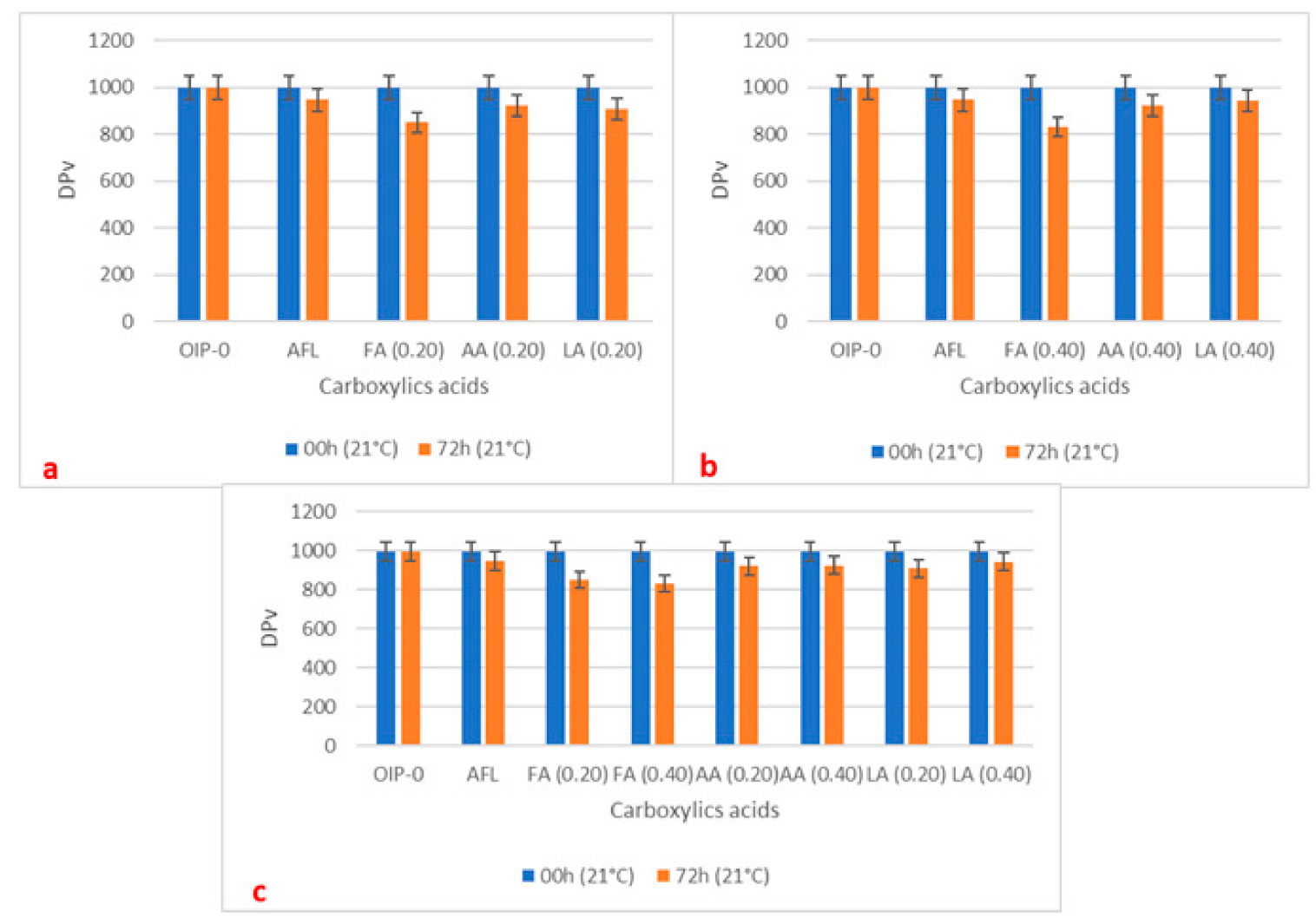

Figure 3. Degree of polymerization before and after $72 \mathrm{~h}$ exposure at room temperature: (a) $0.20 \mathrm{mg}$ $\mathrm{KOH} / \mathrm{g}$ and (b) $0.40 \mathrm{mg} \mathrm{KOH} / \mathrm{g}$ for three different acids (formic, acetic and levulinic), acid mixture and also for acid-free oil. The results are summarized in Figure (c) for better comparison.

While the acidity of oil blended with mixed acids was reduced by almost half after $72 \mathrm{~h}$ of exposure at room temperature, the DPv of the paper samples remained almost unchanged. The acids mixture would delay the release of the $\mathrm{H}+$ proton to cause degradation of paper cellulose.

\subsection{Total Acid Number (TAN) of Oil for Aged Samples}

Figure $4 a-c$ show the evolution of the TAN during aging. In general, there was a decrease in the TAN for all acid concentrations up to $500 \mathrm{~h}$ aging. The absorption of carboxylic acids initially added in oil explains this drop in acidity [16]. This absorption may be related to the reduction in paper's polymerization degree (DPv) at this aging duration, which will be seen later. From $500 \mathrm{~h}$ up to $2000 \mathrm{~h}$ of aging, the TAN increases with aging time. This may be traced to the production of high molecular weight carboxylic acids that could not be absorbed by paper [17]. However, the results in Figure 4a indicate a low value of the TAN for $0.20 \mathrm{mg} \mathrm{KOH} / \mathrm{g}$ of formic acid throughout the aging process. For oil containing $0.40 \mathrm{mg} \mathrm{KOH} / \mathrm{g}$ of formic acid (Figure $4 \mathrm{~b}$ ), a low value of the TAN was observed after $72 \mathrm{~h}$ exposure at room temperature. However, during thermal aging, the TAN of oil with acetic acid was lower after $500 \mathrm{~h}$ (Figure $4 \mathrm{~b}$ ). The TAN of oil with formic and levulinic acids remained lower for 
1500 and $2000 \mathrm{~h}$ aging, while the TAN of oil with mixed acid suddenly increased up close to $2000 \mathrm{~h}$ of aging. The increase in the TAN of oil with mixed acids during aging can certainly be traced to the generation of high molecular weight acids resulting from oil and paper degradation $[6,8,16,18]$. These findings are confirmed by partitioning studies reported by Lungaard et al. $[8,18]$. Indeed, at increasing temperature, more acids are moved to the oil due to an increased solubility with an activation energy much higher for formic acids.

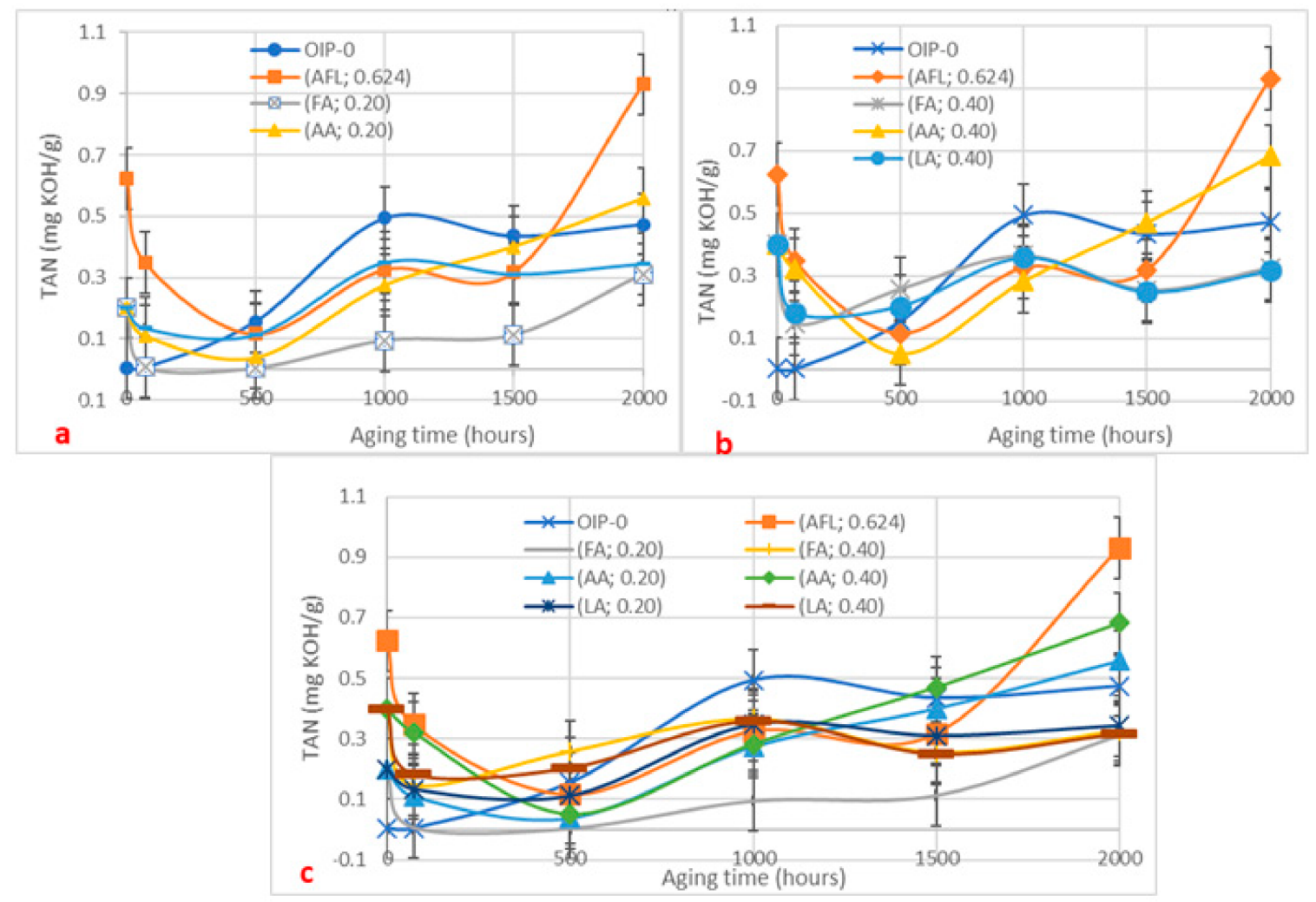

Figure 4. TAN (Total Acid Number) in oil as function of aging duration, for samples mixed with three different acids (formic, acetic and levulinic): (a) $0.20 \mathrm{mg} \mathrm{KOH} / \mathrm{g}$ and (b) $0.40 \mathrm{mg} \mathrm{KOH} / \mathrm{g}$ for three different acids (formic, acetic and levulinic), acid mixture and also for acid-free oil. The results are summarized in Figure (c) for better comparison.

\subsection{The Degree of Polymerisation (DPv) during Thermal Aging}

Figure 5a shows a comparison of the degree of polymerisation (DPv) of paper impregnated with oil containing formic acid as well as oil-free acids as function of aging duration. Generally speaking, the DPv of all samples aged in oils with both acid concentrations of 0.20 and $0.40 \mathrm{mg} \mathrm{KOH} / \mathrm{g}$ decreased with aging, as expected. Some of the trend variations in the $\mathrm{DPv}$ values could be due to recombination of polymer bonds [31].

The higher amount of levulinic acid initially in oil would cause scission of bonds into the entire amorphous zone of paper up to $500 \mathrm{~h}$, after which it would be impossible to cause bonds scission into the crystalline zone.

The DPv of paper aged in oil blended with formic acid decreased more rapidly than oils mixed with the other two acids (acetic and levulinic), regardless of the concentration. Figure 6a represents the $\mathrm{DPv}$ as function of aging for paper aged in oil blended with the mixture of three acids at a concentration of $0.624 \mathrm{mg} \mathrm{KOH} / \mathrm{g}$, compared to those aged in oil with formic acid of both acid concentrations ( 0.20 and $0.40 \mathrm{mg} \mathrm{KOH} / \mathrm{g}$ ). The DPv of paper aged in oil blended with formic acid for both acid concentrations decreased more rapidly than those aged with the acid mixture of $0.624 \mathrm{mg}$ 
$\mathrm{KOH} / \mathrm{g}$. From $500 \mathrm{~h}$ of aging, the DPv of paper aged in oil blended with the mixture of acids decreased more slowly, but remained relatively high. The bulkiness of these acids in oil could have certainly delay their dissolution.

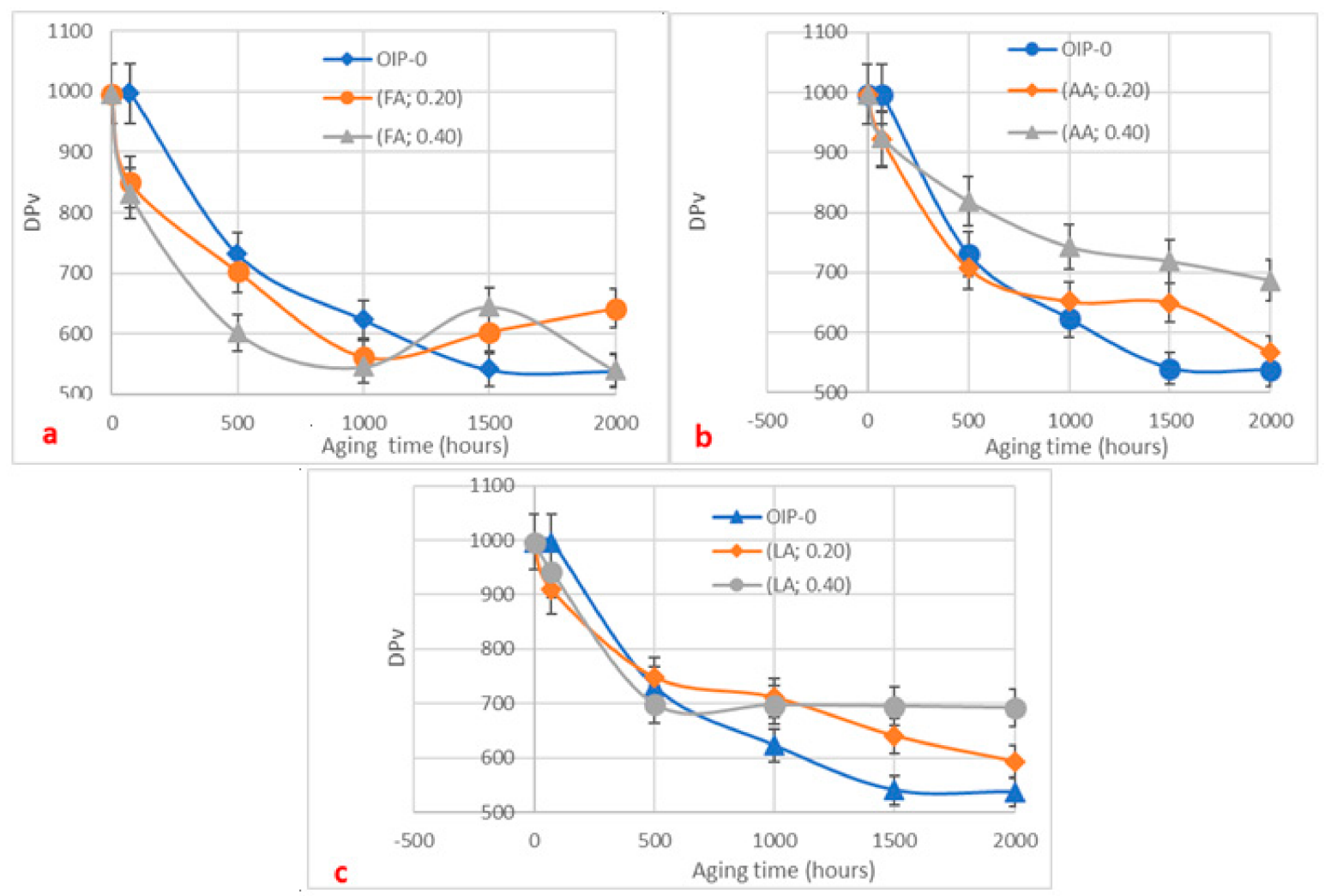

Figure 5. Fall in degree of polymerization (DPv) of paper during aging, for paper samples aged in oil mixed with three different acids (formic, acetic and levulinic) and virgin oil: (a) $0.20 \mathrm{mg} \mathrm{KOH} / \mathrm{g}$ and (b) $0.40 \mathrm{mg} \mathrm{KOH} / \mathrm{g}$ for three different acids (formic, acetic and levulinic), acid mixture and also for acid-free oil. The results are summarized in Figure (c) for better comparison.

In Figure 6, the DPv of the paper samples aged in different conditions is plotted against aging duration. The DPv of papers aged in acetic-acid-blended oil $(0.20 \mathrm{mg} \mathrm{KOH} / \mathrm{g})$ and in the acid mixture at $0.624 \mathrm{mg} \mathrm{KOH} / \mathrm{g}$ decreased more rapidly with aging compared to those aged in acetic-acid-blended oil at $0.40 \mathrm{mg} \mathrm{KOH} / \mathrm{g}$. However, the DPv within oil blended with acetic acid of $0.40 \mathrm{mg} \mathrm{KOH} / \mathrm{g}$ remained higher. This result shows that the concentration of acetic acid is a limiting factor in the degree of paper polymerization. Large concentrations of acetic acid increases the DPv paper [32].

The DPv of paper aged in oil blended with levulinic acid $(0.20$ and $0.40 \mathrm{mg} \mathrm{KOH} / \mathrm{g})$ and oil blended with the acid mixture at $0.624 \mathrm{mg} \mathrm{KOH} / \mathrm{g}$ decreased to $30 \%$ after $500 \mathrm{~h}$ aging. The values remained almost constant for oil blended with levulinic acid at $0.40 \mathrm{mg} \mathrm{KOH} / \mathrm{g}$, while those of paper aged in oil blended with levulinic acid at $0.20 \mathrm{mg} \mathrm{KOH} / \mathrm{g}$ and the acid mixture were still decreasing. Reduction in the DPv might be traced to breaking of $\beta 1-4$ glucosidic bonds of amorphous cellulose regions [27]. High acid concentrations $(0.40 \mathrm{mg} \mathrm{KOH} / \mathrm{g})$ of levulinic acid could cause all these bonds to break in this amorphous region from the first $500 \mathrm{~h}$ of aging. With no more amorphous regions [27], scission of bonds in the crystalline region of cellulose is virtually impossible, which could explain the stability of the DPv decrease from $500 \mathrm{~h}$ to $2000 \mathrm{~h}$ of aging. 


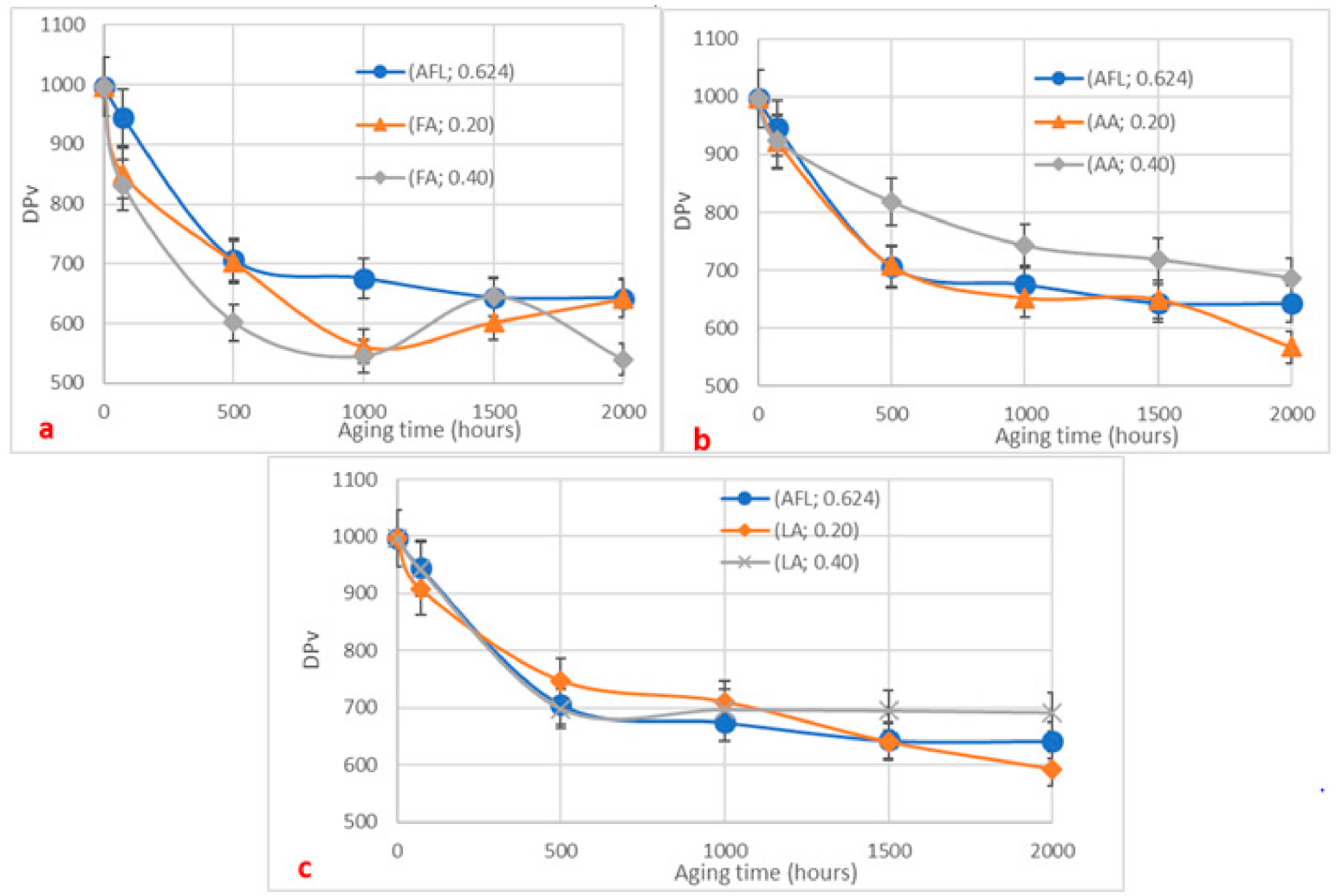

Figure 6. Degree of Polymerization (DPv) of paper as a function of aging in oil blended with acid mixture of $0.624 \mathrm{mg} \mathrm{KOH} / \mathrm{g}$, compared to samples aged in three different acids (formic, acetic and levulinic): (a) $0.20 \mathrm{mg} \mathrm{KOH} / \mathrm{g}$ and (b) $0.40 \mathrm{mg} \mathrm{KOH} / \mathrm{g}$ for three different acids (formic, acetic and levulinic), acid mixture and also for acid-free oil. The results are summarized in Figure (c) for better comparison.

Figure 7 represents the degree of polymerization as function of paper aging in oil within an acid mixture at $0.624 \mathrm{mg} \mathrm{KOH} / \mathrm{g}$ compared to acid-free oil (neutral oil).

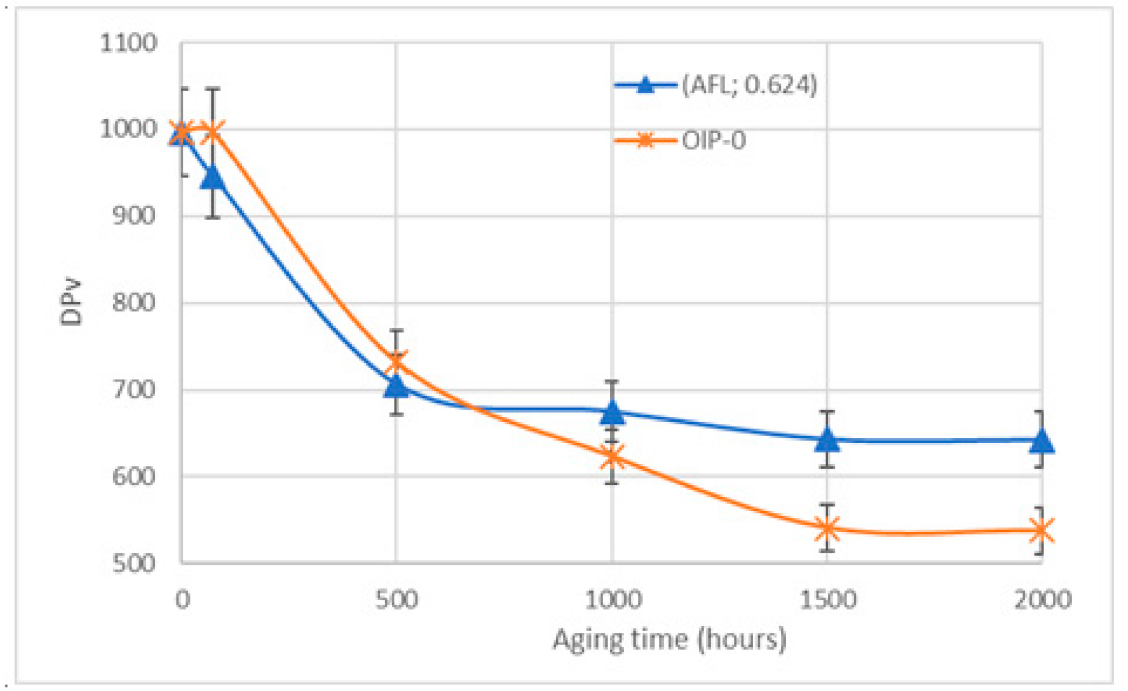

Figure 7. DPv of paper samples aged in oil blended with $0.624 \mathrm{mg} \mathrm{KOH} / \mathrm{g}$ of the three acids compared to those aged in virgin oil as a function of aging duration. 
Figure 7 shows that the DPv of paper aged in oil with the acid mixture was less than those aged in virgin oil up to $500 \mathrm{~h}$ of aging. From $500 \mathrm{~h}$ to $2000 \mathrm{~h}$ of aging, the DPv of paper aged in the presence of acid mixture became and remained higher than those aged in virgin oil.

By looking at Figure 1, it can be seen that up to $1000 \mathrm{~h}$ of aging, the moisture in insulating paper impregnated in both virgin oil (OIP) and the acid oil (AFL) remained high $(>4 \%)$ which represents a critical value in transformers. At the same time, looking at Figure 4, it can be seen that during the first $500 \mathrm{~h}$ of aging, the acidity in the acid oil decreased rapidly from a value of about $0.6 \mathrm{mg} \mathrm{KOH} / \mathrm{g}$ to about $0.1 \mathrm{mg} \mathrm{KOH} / \mathrm{g}$. This can be explained by the reaction of acid with the water molecules leading to a faster degradation of the insulating paper compared to the paper impregnated in virgin oil (OIP), where the acidity increased slightly due to oxidation phenomena during the first $500 \mathrm{~h}$.

After this period, acidity increased gradually with aging in the two samples, but was more significant in the virgin oil than in the acid oil. However, in AFL, the moisture content of the paper (Figure 1) decreased brusquely to a value of $3.5 \%$ and then to $2.5 \%$, at the same time the acidity increased sharply after $1500 \mathrm{~h}$. This supports the idea that moisture and low molecular acids have a multiplicative effect $[12,16,18]$. This trade-off between acidity and humidity can lead to a compromise, which explains the "pseudo-variation" of the DPv (which decreased very slightly after $500 \mathrm{~h}$ of aging). In comparison, in OIP, humidity remained high throughout the aging period, at $>3.5 \%$, while the acidity increased gradually, which explains the decrease in DPv over time. Therefore, oil blended with acid mixture has a less harmful impact on the paper compared to virgin oil.

\section{Conclusions}

It is well established that the production of carboxylic acids during oil-impregnated paper aging results in a reduction in the degree of polymerization. In this paper, the effect of different carboxylic acids on the paper insulation degradation was studied. Because low molecular weight acids (LMA) are readily absorbed into the cellulose fibers, while high molecular weight acids (HMA) are not (because of their hydrophobic character), samples were aged in oil blended with different LMAs (formic, acetic and levulinic) at different concentrations. A mixture of these acids was also considered along with virgin oil to provide a baseline for comparison. From the obtained results, it was found that paper more readily absorbed formic acid than the acetic and levulinic acids. The aging rate of the paper was therefore more significant for samples aged in formic-acid-blended oil.

From these investigations, it may be concluded that present diagnostic techniques for monitoring insulation oil conditions based on the total acid number (which is used as reclamation criterion) does not provide a true picture of the transformer condition, since this procedure cannot distinguish between different acid types and their influences. Knowledge of the evolution of LMAs can be of great help to managers of transformer fleets, since the state of the dielectric paper determines the service life of a power transformer. New measuring techniques allowing discrimination of low molecular weight acids will be helpful in monitoring the condition of the solid insulation system.

Author Contributions: This work was done under the supervision of I.F., holder of the Research Chair on the Aging of Power Network Infrastructure (ViAHT), L.C. and K.A.D. (professors at Université Félix Houphouet Boigny) who designed this research and gave the whole guidance. K.D.K., Y.H. and K.M.L.Y. collected all the data, carried out calculations, result display and analysis and wrote the manuscript. The final draft of paper was thoroughly reviewed by I.F., L.C. and K.A.D. All authors read and approved the final manuscript.

Acknowledgments: This work was partially sponsored by the Natural Sciences and Engineering Research Council of Canada (NSERC) under Grant No. RGPIN-201504403. Thanks are also extended to the Government of Ivory Coast for supporting the research stay of Kakou in Canada.

Conflicts of Interest: The authors declare no conflicts of interest.

\section{References}

1. N'Cho, J.S.; Fofana, I.; Beroual, A. Review of Modern Physicochemical-based Diagnostic Techniques for Assessing Insulation condition in Aged Transformers. Energies 2016, 9, 367. [CrossRef] 
2. Fofana, I.; Hadjadj, Y. Electrical-based Diagnostic Techniques for Assessing Insulation condition in Aged Transformers. Energies 2016, 9, 679. [CrossRef]

3. Peng, L.; Fu, Q.; Zhao, Y.; Qian, Y.; Chen, T.; Fan, S. A Non-Destructive Optical Method for the DP Measurement of Paper Insulation Based on the Free Fibers in Transformer Oil. Energies 2018, 11, 716. [CrossRef]

4. Godina, R.; Rodrigues, E.M.G.; Matias, J.C.O.; Catalão, J.P.S. Effect of Loads and Other Key Factors on Oil-Transformer Ageing: Sustainability Benefits and Challenges. Energies 2015, 8, 12147-12186. [CrossRef]

5. Cheng, L.; Yu, T. Dissolved Gas Analysis Principle-Based Intelligent Approaches to Fault Diagnosis and Decision Making for Large Oil-Immersed Power Transformers: A Survey. Energies 2018, 11, 913. [CrossRef]

6. Wang, X.; Tang, C.; Huang, B.; Hao, J.; Chen, G. Review of Research Progress on the Electrical Properties and Modification of Mineral Insulating Oils Used in Power Transformers. Energies 2018, 11, 487. [CrossRef]

7. Ward, B. Application of Filtration System for On-Line Oil Reclamation, Degassing, and Dehydration; Report No. 1002046; Electric Power Research Institute (EPRI): Palo Alto, CA, USA, 2003.

8. Fofana, I.; Sabau, J. The Service Reliability of Aging Power Transformers. In Proceedings of the Cigré Canada Conference, Calgary, AB, Canada, 9-11 December 2013.

9. Erdman, H.G. Electrical Insulating Oils, STP 998; ASTM International: West Conshohocken, PA, USA, 1988.

10. Xiang, Q.; Lee, Y.; Pettersson, P.O.; Torget, R.W. Heterogeneous aspects of acid hydrolysis of $\alpha$-cellulose. In Biotechnology for Fuels and Chemicals; Number 1-3 Spring; Humana Press Inc.: New York, NY, USA, 2003; Volumes 107, pp. 505-514. ISSN 0273-2289.

11. Mineral Insulating Oils in Electrical Equipment. Supervision and Maintenance Guidance; IEC 60422 ed. 4.0; IEC International: Geneva, Switzerland, 2013.

12. Lelekakis, N.; Wijaya, J.; Martin, D.; Susa, D. The effect of acid accumulation in power-transformer oil on the aging rate of paper insulation. IEEE Electr. Insul. Mag. 2014, 30, 19-26. [CrossRef]

13. Martin, D.; Perkasa, C.; Lelekakis, N. Measuring paper water content of transformers: A new approach using cellulose isotherms in nonequilibrium conditions. IEEE Trans. Power Deliv. 2013, 28, 1433-1439. [CrossRef]

14. Lelekakis, N.; Martin, D.; Wijaya, J. Ageing rate of paper insulation used in power transformers Part 1: Oil/paper system with low oxygen concentration. IEEE Trans. Dielectr. Electr. Insul. 2012, 19, 1999-2008. [CrossRef]

15. Lelekakis, N.; Martin, D.; Wijaya, J. Ageing rate of paper insulation used in power transformers Part 2: Oil/paper system with medium and high oxygen concentration. IEEE Trans. Dielectr. Electr. Insul. 2012, 19, 2009-2018. [CrossRef]

16. Lundgaard, L.E.; Hansen, W.; Ingebrigtsen, S. Ageing of Mineral Oil impregnated Cellulose by Acid Catalysis. IEEE Trans. Dielectr. Electr. Insul. 2008, 15, 540-546. [CrossRef]

17. Ingebrigtsen, S.; Dahlund, M.; Hansen, W.; Linhjell, D.; Lundgaard, L.E. Solubility of carboxylic acids in paper (Kraft)-oil insulation systems. In Proceedings of the 2004 Annual Report Conference on Electrical Insulation and Dielectric Phenomena (CEIDP '04), Boulder, CO, USA, 17-20 October 2004; pp. 253-257.

18. Lundgaard, L.E.; Hansen, W.; Ingebrigtsen, S.; Linhjell, D.; Dahlund, M. Aging of Kraft paper by acid catalyzed hydrolysis. In Proceedings of the 2005 IEEE International Conference on Dielectric Liquids (ICDL 2005), Coimbra, Portugal, 26 June-1 July 2005; pp. 381-384.

19. CIGRE Task Force D1.01.10. Ageing of Cellulose in Mineral-Oil Insulated Transformers; CIGRE Technical Brochure No 323; CIGRE: Paris, France, 2007; 88p.

20. Bandara, K.; Ekanayake, C.; Saha, T.; Ma, H. Performance of Natural Ester as a Transformer Oil in Moisture-Rich Environments. Energies 2016, 9, 258. [CrossRef]

21. Ivanov, K.I.; Panfilova, E.S.; Kullkovskaya, T.N.; Zhakhovskaya, V.P.; Savinova, V.K.; Seminova, M.G. Effect of petroleum oil oxidation products on the ageing of paper insulation in transformers. Zh. Prikl. Khim. (Leningrad) 1974, 47, 2705-2711.

22. Prabhashankar, V.; Badkas, D.J. Mechanism of Oxidation of Transformers Oils. J. Inst. Petr. 1961, 47, $201-211$.

23. Hill, G.C.; Holman, J.S. Chemistry in Context, 5th ed.; Nelson: Walton-onThames, UK, 2000.

24. Krassig, H.; Schurz, J. Cellulose. In Ullmann's Encyclopedia of Industrial Chemistry, 6th ed.; Wiley: Hoboken, NJ, USA, 2002.

25. Ruelle, J. Analyse de la Diversité du Bois de Tension de 3 Espèces D'angiospermes de Forêt Tropicale Humide de Guyane Française. Ph.D. Thesis, Université des Antilles et de la Guyane, Cayenne, France, 2006. 
26. Lin, J.S.; Tang, M.Y.; Fellers, J.F. Fractal Analysis of cotton cellulose as characterized by small angle X-ray scattering. In The Structures of Cellulose. ACS Symposium Series; Atalla, R.H., Ed.; American Chemical Society: Washington, DC, USA, 1987; Volume 340, pp. 233-254.

27. Zeronian, S.H. Intercrystalline swelling of cellulose. In Cellulose Chemistry and Its Applications; Horwood: Chichester, UK, 1985; pp. 138-158.

28. Ojha, S.K.; Purkait, P.; Chakravorti, S. Evaluating the effects of lower molecular weight acids in oil-paper insulated transformer. In Proceedings of the 2017 3rd International Conference on Condition Assessment Techniques in Electrical Systems (CATCON), Rupnagar, India, 16-18 November 2017.

29. Wan, F.; Du, L.; Chen, W.; Wang, P.; Wang, J.; Shi, H. A Novel Method to Directly Analyze Dissolved Acetic Acid in Transformer Oil without Extraction Using Raman Spectroscopy. Energies 2017, 10, 967. [CrossRef]

30. Petrucci, R.H.; Harwood, W.S.; Herring, F.G. General Chemistry, 8th ed.; Prentice-Hall: Upper Saddle River, NJ, USA, 2002; p. 666.

31. Fellers, C.; Iversen, T.; Lindström, T.; Nilsson, T.; Rigdahl, M. Ageing/Degradation of Paper-A Literature Survey; Riksarkivet: Stockholm, Sweden, 1989; ISSN 0284-5636.

32. Kakou, D.; Cissé, L.; Fofana, I.; Hadjadj, Y.; Yapi, K.M.L.; Ambroise, D.K. Impact of Acidity on the Degradation of the Solid Insulation of Power Transformer. In Proceedings of the 20th International Symposium on High Voltage Engineering (ISH 2017), Buenos Aires, Argentina, 28 August-1 September 2017.

(c) 2018 by the authors. Licensee MDPI, Basel, Switzerland. This article is an open access article distributed under the terms and conditions of the Creative Commons Attribution (CC BY) license (http://creativecommons.org/licenses/by/4.0/). 